\title{
Yrusta v. Argentina: la desaparición forzada por un periodo breve
}

\author{
Yrusta v. Argentina: Short Term Enforced \\ Disappearance
}

María Clara Galvis Patiño*

Recepción: 20/09/20

Evaluación: 21/10/20

Versión final: $03 / 11 / 20$

Resumen: El artículo comenta el primer dictamen del Comité contra la Desaparición Forzada. Según el Comité, el ocultamiento, por más de siete días, del paradero de una persona que inicialmente estaba legítimamente privada de la libertad, cumpliendo su condena en una cárcel oficial del Estado, constituye desaparición forzada y detención en secreto, a la luz de la Convención internacional para la protección de todas las personas contra las desapariciones forzadas. El artículo ilustra la aplicación al caso sometido a consideración del Comité de algunos de los aspectos novedosos de esta convención, que fortalecen la protección internacional frente a las desapariciones forzadas, como el derecho a no ser sometido a desaparición forzada y la prohibición de detención en secreto. También se refiere al llamado "elemento temporal" de la desaparición forzada y resalta la posición tomada por el Comité sobre el particular.

Palabras clave: desaparición forzada, detención en secreto, desaparición forzada por un periodo breve, Comité contra la Desaparición Forzada.

* Docente-investigadora de la Universidad Externado de Colombia, Bogotá, Colombia. Correo electrónico: maria.galvis@uexternado.edu.co. Agradezco a quien hizo la revisión ciega de este artículo, a Rainer Huhle y a Oswaldo Arias Avila por sus valiosos comentarios. 


\begin{abstract}
The article comments the first view of the Committee against enforced disappearance. According to the Committee, the concealment, for more than seven days, of the whereabouts of a person that was initially legitimately deprived of liberty, and serving his sentence in an official prison, constitutes enforced disappearance and secret detention, in the light of the International Convention for the protection of all persons from enforced disappearances. The article illustrates the application to the case submitted to the Committee of some of the important progress and novel aspects introduced by this Convention in order to enhance the international protection against enforced disappearances, such as the right not to be subjected to an enforced disappearance and the prohibition to be held in secret detention. The article refers to the so-called "temporal element" of the enforced disappearance and highlights the position set by the Committee in this regard.
\end{abstract}

Key words: forced disappearance, secret detention, short term enforced disappearance, Committee against Enforced Disappearance.

\title{
1. Introducción
}

En el proceso de configuración de la desaparición forzada como ilícito internacional, la primera decisión judicial, en el ámbito del derecho internacional de los derechos humanos, se encuentra en la sentencia de la Corte Interamericana de Derechos Humanos (en adelante también "Corte Interamericana” o "Corte IDH”), en el caso Velásquez Rodríguez v. Honduras (Corte IDH, 1988). Allí, la Corte Interamericana, sin una norma positiva de derecho internacional que definiera la conducta ilícita, estableció, entre otros aspectos, que la desaparición forzada es una violación autónoma de derechos humanos convencionales, y declaró que el Estado hondureño violó, en perjuicio del señor Ángel Manfredo Velásquez Rodríguez, varios derechos consagrados en la Convención Americana sobre Derechos Humanos (en adelante también "Convención Americana" o "CADH").

Con el mismo objetivo de proteger a los seres humanos contra las desapariciones forzadas y sin que existiera en ese entonces un instrumento internacional específico, desde 1980, el Grupo de Trabajo sobre Desapariciones 
Forzadas o Involuntarias de las Naciones Unidas (CDH, 1980) realiza sus labores, mediante procedimientos no judiciales.

Posteriormente, gracias al impulso, entre otros, de familiares y de asociaciones de familiares de personas desaparecidas, se adoptaron los primeros instrumentos internacionales de protección contra la desaparición forzada: la Declaración sobre la protección de todas las personas contra las desapariciones forzadas (ONU, 1992) y la Convención Interamericana sobre Desaparición Forzada de Personas (OEA, 1994), (en adelante, también "Convención Interamericana" o "CISDFP"). En 2006, la Asamblea General de las Naciones Unidas aprobó la Convención internacional para la protección de todas las personas contra las desapariciones forzadas (ONU, 2006), (en adelante también "Convención Internacional”), tratado que contiene disposiciones que brindan una protección más robusta que los instrumentos internacionales de la década anterior, dirigidas a la prevención de las desapariciones forzadas, a la lucha contra la impunidad del delito de desaparición forzada y al respeto y garantía de los derechos de las víctimas a la justicia y a la reparación (ONU, 2006, preámbulo).

El objetivo de este artículo es comentar el primer dictamen del Comité contra la Desaparición Forzada (en adelante también "Comité"), adoptado el 11 de marzo de 2016, en el caso Yrusta v. Argentina, cuyos hechos, ocurridos en democracia, recuerdan que la desaparición forzada se comete también en contextos democráticos y no únicamente en conflictos armados, dictaduras o regímenes autoritarios.

En este dictamen, el Comité interpretó y aplicó por primera vez en un caso individual la Convención internacional para la protección de todas las personas contra las desapariciones forzadas. Aparte de ser el primer dictamen, con el que se inicia la jurisprudencia del Comité en materia de comunicaciones individuales, el caso Yrusta v. Argentina tiene importancia por los temas que aborda, que dejan ver, con la claridad de su aplicación en un caso concreto, la relevancia de la Convención Internacional para una mayor protección de todas las personas contra las desapariciones forzadas. En este sentido, en cada uno de los apartes, el artículo resalta los avances tanto de la Convención Internacional como de la interpretación realizada por el Comité en el caso Yrusta v. Argentina. 
Inicialmente, el artículo presenta los hechos que dieron lugar a la intervención del Comité y que sirven de fundamento a su decisión. Posteriormente, aborda algunos temas que representan los avances de la Convención Internacional en materia de prevención de la desaparición forzada, lucha contra la impunidad y derechos de las víctimas a la verdad, a la justicia y a la reparación, que el Comité abordó en el caso Yrusta v. Argentina. En este contexto, los temas que el artículo trata, en su orden, son: i) el derecho de toda persona a no ser sometida a desaparición forzada, ii) la irrelevancia, para la configuración de la conducta de desaparición forzada, del tiempo de duración del ocultamiento de la suerte o paradero de la persona que ha sido privada de la libertad, iii) el derecho de toda persona a no ser detenida en secreto, iv) las obligaciones estatales que la Convención Internacional estableció para prevenir esta práctica, relativas a establecer y mantener registros oficiales de las personas privadas de libertad, v) el derecho a garantizar el acceso a dicha información a quienes tengan interés legítimo en la información que repose en esos registros oficiales y vi) la obligación estatal de investigar la desaparición forzada y no solo la muerte causada con posterioridad al cese del primer ilícito.

El artículo finaliza con una breve reflexión sobre la importancia del papel de las autoras de la comunicación y unas conclusiones sobre el valor y alcance de este primer dictamen del Comité contra la Desaparición Forzada.

\section{Hechos relevantes del caso Yrusta v. Argentina}

Roberto Agustín Yrusta fue condenado, en diciembre de 2005, a ocho años de prisión por los delitos de robo con arma de fuego y porte de arma de guerra, y recluido en una cárcel oficial, en la provincia de Córdoba, en Argentina. El señor Yrusta denunció ante los tribunales de esta provincia a miembros del Servicio Penitenciario por las torturas a las que había sido sometido durante su privación de libertad, que incluían permanencia en celdas de castigo por largos periodos, asfixia con bolsa de nailon, golpes, amenazas, cama de sujeción encadenado. También denunció públicamente estos hechos en una entrevista en un programa de televisión. Luego de las denuncias, las torturas y malos tratos se agravaron. 
Dado que temía por su vida, solicitó el traslado a la provincia de Santiago del Estero, donde vivía parte de su familia. No obstante, fue trasladado a la provincia de Santa Fe. Sus hermanas preguntaron varias veces, durante más de siete días, a las autoridades penitenciarias, por el paradero de Roberto Agustín. No obtuvieron respuesta alguna ni fueron informadas sobre el lugar al que había sido trasladado su hermano. Al entrar nuevamente en contacto con sus hermanas, vía telefónica, les contó que desde su llegada a la cárcel en la provincia de Santa Fe había sido torturado diariamente con detención en celdas de castigo, custodia para realizar llamadas telefónicas y falta de atención médica.

Meses antes de que el señor Yrusta pudiera acceder a la libertad asistida y a su libertad definitiva, las autoridades penitenciarias de la Provincia de Santa Fe comunicaron a sus familiares que su hermano se había suicidado ahorcándose. Dadas las características que tenía el cuerpo cuando les fue entregado (heridas y cortes en varias partes del cuerpo, hematomas, un golpe en la cabeza y signos de impactos de balas de goma), las hermanas del señor Yrusta desconfiaron de la versión de las autoridades.

Las hermanas de Roberto Agustín consideraron que este fue desaparecido, habida cuenta que durante los más de siete días que siguieron a su traslado a Santa Fe, el paradero de su hermano les fue ocultado, a pesar de las reiteradas solicitudes de información dirigidas a las autoridades penitenciarias de su país.

Los hechos de los que fue víctima el señor Roberto Agustín Yrusta seguidos de la falta de una respuesta adecuada y diligente de las autoridades de investigación penal argentinas dieron lugar al primer dictamen del Comité contra la Desaparición Forzada.

\section{El derecho de toda persona a no ser sometida a desapa- rición forzada}

El primer aspecto que aborda el Comité contra la Desaparición Forzada en su dictamen en el caso Yrusta v. Argentina es el relativo al derecho de toda persona a no ser sometida a desaparición forzada, cuya consagración en la Convención Internacional es uno de sus rasgos distintivos y constituye 
un avance importantísimo en la evolución del derecho internacional de los derechos humanos en materia de desaparición forzada.

El texto de la Convención internacional para la protección de todas las personas contra las desapariciones forzadas comienza afirmando categóricamente que "nadie será sometido a una desaparición forzada" (ONU, 2006, artículo 1). El carácter absoluto de la prohibición se hace evidente en que la Convención Internacional precisa con claridad que en "ningún caso podrán invocarse circunstancias excepcionales tales como estado de guerra, amenaza de guerra, inestabilidad política interna o cualquier otra emergencia pública como justificación de la desaparición forzada" (ONU, 2006, artículo 1.2). De esta manera, el derecho de toda persona a no ser sometida a desaparición forzada fue instituido por los redactores de la Convención Internacional mediante su prohibición absoluta.

En el artículo 2, la Convención Internacional consagra las dos conductas que configuran una desaparición forzada ${ }^{1}: 1$ ) la privación de la libertad de cualquier forma (arresto, detención, secuestro u otra), por parte de agentes estatales o por personas o grupos de personas que actúan con la autorización, el apoyo o la aquiescencia del Estado seguida de 2) la negativa a reconocer dicha privación o del ocultamiento de la suerte o paradero de la persona desaparecida.

En el caso Yrusta, el Comité sostuvo, en relación con el primer elemento de una desaparición forzada, que de acuerdo con el artículo 2 de la Convención Internacional, la conducta puede iniciar con una detención ilegal o con una detención inicialmente legal, "como en el presente caso, con ocasión de un traslado" (CED, 2016, párr. 10.3). Este traslado fue decidido

1 A partir de las definiciones de los instrumentos internacionales específicos sobre desaparición forzada (la Declaración de 1992 sobre la protección de todas las personas contra las desapariciones forzadas y las convenciones interamericana sobre desaparición forzada de personas, de 1994, e internacional para la protección de todas las personas contra las desapariciones forzadas, de 2006), un sector amplio de la doctrina sostiene que la desaparición forzada exige tres elementos o requisitos para su configuración. Fabián Salvioli, miembro del Comité, con quien coincido, considera que la desaparición forzada exige dos elementos relativos a la conducta y que el requisito personal no está referido a la conducta sino a la cualificación de la persona que comete una desaparición forzada. Se trata entonces de dos criterios en torno a una misma definición: uno que encuentra tres requisitos, sin distinguir la naturaleza de cada uno de ellos, y otro criterio que identifica dos elementos de conducta y un elemento personal. 
por las autoridades penitenciarias mientras el señor Yrusta estaba privado de su libertad de manera legal, por orden de una autoridad judicial penal de su país.

En cuanto al segundo elemento de una desaparición forzada, el Comité consideró que "la falta de respuesta de las autoridades penitenciarias a las peticiones de información de la familia del Sr. Yrusta sobre su paradero, así como la falta de información sobre lo ocurrido durante los más de siete días en los cuales el paradero del Sr. Yrusta quedó desconocido, constituyen un ocultamiento de su suerte o paradero" (CED, 2016, párr. 10.4). Agregó el Comité que durante esos días Roberto Agustín Yrusta no pudo comunicarse con nadie ni recibir visitas y ni él ni su familia tuvieron acceso a un tribunal que determinara la legalidad de su situación durante el traslado de un centro penitenciario a otro.

El Comité concluyó que los actos de los que fue objeto el señor Yrusta durante los más de siete días siguientes a su traslado a una cárcel en la provincia de Santa Fe configuran una desaparición forzada, que implica la violación de los artículos 1 y 2 de la Convención Internacional.

Como se puede observar a partir del razonamiento y conclusiones del Comité, el caso Yrusta v. Argentina es el primer pronunciamiento en el sistema universal de protección de derechos humanos, con base en una fuente convencional, sobre la responsabilidad internacional del Estado por la violación del derecho de toda persona a no ser sometida a desaparición forzada, protegido -como quedó dicho arriba- mediante la prohibición absoluta establecida en el artículo 1 de la Convención Internacional. Hasta entonces, este derecho sólo había sido desarrollado, sin fuente convencional, por la jurisprudencia del sistema interamericano, como derecho autónomo, y por la jurisprudencia del sistema universal, como violación de varios derechos con la conducta de desaparición forzada. A continuación se mencionan estos desarrollos jurisprudenciales, que preceden al caso Yrusta.

En el ámbito universal, el Comité de Derechos Humanos, desde la década de los 80, con fundamento en el Pacto de Derechos Civiles y Políticos (en adelante también "Pacto" o "PDCP"), ha declarado la responsabilidad de los Estados, en casos con los elementos que en la actualidad son considerados como constitutivos de una desaparición forzada, por 
la violación de varios derechos consagrados en este tratado, a saber: los derechos a la vida; a no ser sometido a torturas ni a penas o tratos crueles, inhumanos o degradantes; a la libertad e integridad personales; a recibir un trato humano y con el respeto debido a la dignidad inherente al ser humano durante la privación de la libertad y al reconocimiento de su personalidad jurídica.

Las características y el contenido del tratado que debe interpretar y aplicar el Comité de Derechos Humanos, un tratado de carácter general que no contiene en su texto el derecho de las personas a no ser sometidas a desaparición forzada ni prohíbe esta práctica, lo han llevado a desarrollar en sus dictámenes sobre comunicaciones individuales el derecho a no ser sometido a desaparición forzada, como una violación de varios derechos protegidos por el Pacto.

En sus primeros dictámenes, entre 1980 y 1982, el Comité de Derechos Humanos decidió varias comunicaciones ${ }^{2}$ en las que dio por probada la detención sin orden judicial y la negativa de las autoridades uruguayas a dar información sobre el paradero de las personas detenidas, sin calificar los hechos como desaparición forzada. En 1983, luego de concluir que Elena Quinteros fue detenida por la Policía de Uruguay en territorio de la embajada de Venezuela en este país y encerrada en un centro de detención militar donde fue torturada, concluyó, así mismo, que "la responsabilidad por la desaparición de Elena Quinteros incumbe a las autoridades del Uruguay" (CCPR, 1983, párr. 16). Esta responsabilidad, bajo el Pacto de Derechos Civiles y Políticos, implicó, según el Comité, el incumplimiento de las obligaciones de respetar los derechos de Elena Quinteros a no ser sometida a tortura (artículo 7), a la libertad y a la seguridad personales (artículo 9) y a ser tratada humanamente y con el respeto debido a la dignidad inherente al ser humano durante la privación de libertad (artículo 10.1).

En las décadas siguientes, la jurisprudencia del Comité de Derechos Humanos continuó evolucionando. Además de los derechos mencionados, el Comité ha considerado que la desaparición forzada también

2 Ver, entre otros, los casos Ismael Weinberger v. Uruguay, Comunicación No. R.7/28, 29 de octubre de 1980; Rosario Pietraroia v. Uruguay, Comunicación No. R.10/44, 27 de marzo de 1981; Eduardo Bleier v. Uruguay, Comunicación No. R.7/30, 29 de marzo de 1982. 
vulnera el derecho a la vida ${ }^{3}$ y el derecho al reconocimiento de la personalidad jurídica. ${ }^{4}$

En el ámbito del sistema interamericano de protección de derechos humanos la situación normativa y jurisprudencial es similar, en lo relativo a la inexistencia convencional de un derecho a no ser sometido a desaparición forzada, y a la vez distinta, en tanto la Corte Interamericana de Derechos Humanos ha adjudicado la responsabilidad estatal por desaparición forzada como violación autónoma, aunque no de manera consistente. ${ }^{5}$ En 1988, en el emblemático caso Velásquez Rodríguez v. Honduras, esta Corte caracterizó la desaparición forzada como una violación de derechos humanos autónoma, grave, compleja, múltiple y continuada, con fundamento en un tratado de carácter general, como la Convención Americana sobre Derechos Humanos, que tampoco consagra el derecho a no ser sometido a desaparición forzada ni prohíbe explícitamente esta práctica. En el sistema interamericano, la fuente jurisprudencial del derecho a no ser sometido a desaparición forzada se mantiene hasta el presente como la única. La Convención interamericana sobre desaparición forzada de personas, aprobada en 1994, aunque significa un progreso importante en la consagración normativa de otros aspectos, tales como la definición de la conducta de desaparición forzada y la afirmación de que su práctica en ningún caso puede justificarse en circunstancias excepcionales (CISDFP, 1994, artículos III y X), no estableció en su texto el derecho a no ser sometido a desaparición forzada. Y la jurisprudencia de la Corte Interamericana de Derechos Humanos ha fundado la prohibición absoluta de la desaparición forzada en el carácter de jus cogens de esta pro-

3 Ver, al respecto, entre otros, los casos El Awani v. Libia, Comunicación No 1295/2004, 29 de agosto de 2007; Bousroual v. Argelia, Comunicación No 992/2001, 26 de abril de 2006; Sarma v. Sri Lanka, Comunicación No 950/2000, 31 de julio de 2003.

4 En los casos Kimouche v. Algeria y Grioua v. Algeria, Comunicaciones No. 1328/2004 y No. 1327/2004, ambos decididos el 10 de julio de 2007, el Comité consideró, por primera vez, la violación del derecho al reconocimiento de la personalidad jurídica en el contexto de una desaparición forzada. Esta línea de decisión se mantiene hasta la fecha. Al respecto, ver, entre otros, Rosa María Serna y otros v. Colombia, Comunicación No. 2134/2012, de 22 de septiembre de 2015 y Christian Téllez Padilla v. México, Comunicación 2750/2016, 5 de agosto de 2019.

5 Acerca de las inconsistencias de la Corte Interamericana de Derechos Humanos sobre este particular, ver Galvis M. (2020a). 
hibición (Corte IDH, 2006), mas no en la Convención Internacional, como bien podría haberlo hecho. ${ }^{6}$

Como se ha mencionado en este artículo, el desarrollo del derecho a no ser sometido a desaparición forzada ha sido, en las circunstancias ya anotadas, meramente jurisprudencial, dadas las características y limitaciones de tratados generales de derechos humanos como el Pacto de Derechos Civiles y Políticos y la Convención Americana sobre Derechos Humanos.

Es entonces un gran avance en la protección internacional contra la desaparición forzada que el comité encargado de interpretar la Convención Internacional haya calificado las acciones y omisiones del Estado argentino en perjuicio de Roberto Agustín Yrusta como constitutivas de desaparición forzada. Así, el primer dictamen del Comité refleja que, además de su valor simbólico, la consagración del derecho a no ser sometido a desaparición forzada en un tratado de alcance universal le da certeza jurídica y fortalece su protección internacional. Sin duda, la protección de un derecho tiene mayor estabilidad cuando los desarrollos jurisprudenciales sobre el mismo se han cristalizado en normas de alcance universal. ${ }^{7}$

\section{La desaparición forzada no depende del tiempo en que una persona permanezca privada de libertad sin que se conozca su paradero}

La doctrina ${ }^{8}$ y la jurisprudencia han debatido sobre si se requiere o no de un elemento temporal para que se califique una conducta como desaparición forzada. La pregunta que subyace a este debate es ¿cuánto tiempo debe durar el ocultamiento de la suerte o paradero de la persona privada de la libertad para que se configure una desaparición forzada? En el derecho internacional de los derechos humanos, ni la Declaración sobre la protección de todas las personas contra las desapariciones forzadas, ni la

6 Sobre el uso que le ha dado la Corte Interamericana en su jurisprudencia sobre desaparición forzada a la Convención internacional para la protección de todas las personas contra las desapariciones forzadas, ver Galvis (2020b).

7 Sobre este particular, ver Galvis (2020a).

8 Ver Citroni (2016). 
Convención interamericana sobre desaparición forzada de personas ni la Convención internacional para la protección de todas las personas contras las desapariciones forzadas incluyen un elemento temporal al definir la conducta de desaparición forzada. Estos instrumentos internacionales solo requieren, para su configuración, i) la privación de libertad (por agentes del estado o particulares que cuentan con su autorización, apoyo o aquiescencia) seguida de ii) la negación de la privación de libertad o del ocultamiento del paradero o suerte de la persona. ${ }^{9}$

Una referencia al elemento temporal aparece en la definición de la desaparición forzada como crimen de lesa humanidad contenida en el Estatuto de Roma, donde se afirma que la conducta debe cometerse "con la intención de dejar [a las personas] fuera del amparo de ley por un periodo prolongado" (Estatuto de Roma, 1998, artículo 7.2.i). El Comité de Derechos Humanos se ha basado en esta definición para sostener que todo acto de desaparición de ese tipo constituye una violación de muchos de los derechos consagrados en el Pacto (CCPR, 2003, 2006 y 2007).

En el caso Aboufaied v. Libia, el Comité de Derechos Humanos consideró que la detención en secreto de los hermanos Idriss y Juma Aboufaied, durante cuatro y quince meses, respectivamente, dio lugar a su desaparición forzada, conducta con la que se violaron sus derechos al reconocimiento de su personalidad jurídica, a la libertad y a la seguridad personales, a no ser sometidos a torturas ni a penas o tratos crueles, inhumanos o degradantes y el derecho de toda persona privada de la libertad a ser tratada humanamente y con el respeto debido a la dignidad inherente al ser humano, todos ellos consagrados en el Pacto Internacional de Derechos Civiles y Políticos (CCPR, 2012, párr. 7.3) El Comité precisó que la desaparición forzada de los hermanos Aboufaied los privó de la protección de la ley durante el periodo en que estuvieron sometidos a detención secreta, en violación de su derecho al reconocimiento como personas ante la ley (CCPR, 2012, párr. 7.10).

9 Ver el considerando tres del preámbulo de la Declaración sobre la protección de todas las personas contra las desapariciones forzadas y los artículos II y 2, respectivamente, de la Convención interamericana sobre desaparición forzada de personas y de la Convención internacional para la protección de todas las personas contras las desapariciones forzadas. 
Esta conclusión del Comité de Derechos Humanos dio lugar a votos particulares de tres de sus miembros: ${ }^{10}$ Nigel Rodley, Walter Kälin y Fabián Salvioli. El primero, si bien coincidió con el dictamen de la mayoría, sostuvo que la detención en secreto por un periodo breve no prueba que la persona haya sido puesta fuera del amparo de la ley y que sin esta desprotección no se puede calificar una detención como desaparición forzada. La distinción entre detención arbitraria y desaparición forzada, en su criterio, "parece incluir un elemento de tiempo en la noción de desaparición forzada” (CCPR, 2012b, párr. 2). Al experto Rodley le preocupaba que la consideración como desaparición forzada de detenciones secretas por plazos relativamente breves pudiera banalizar la desaparición forzada.

Por su parte, Walter Kälin se apartó de la decisión de la mayoría, en relación con la situación de Idriss (detenido en secreto en dos ocasiones por un tiempo de dos meses cada vez), por considerar que el derecho al reconocimiento de la personalidad jurídica se vulnera solo cuando las víctimas son privadas "por un periodo prolongado de toda posibilidad de ejercer sus derechos" y se les niega el acceso a un recurso contra esas violaciones (CCPR, 2012c, párr. 4).

El voto del experto Salvioli, si bien es parcialmente disidente en lo que tiene que ver con las consideraciones del Comité sobre la violación del derecho a la vida, en lo atinente al tiempo mínimo requerido para que una detención sea considerada como desaparición forzada, coincide con la decisión de la mayoría. Aunque a él también le preocupaba que la noción de desaparición forzada se debilitara, sus razones son diferentes y tienen un sentido distinto a las expresadas por el experto Rodley: se encuentran en el riesgo que implicaría introducir la "dimensión temporal" como un elemento adicional de la conducta. Ello podría tener consecuencias graves al demorar la activación de las acciones urgentes previstas en los instrumentos internacionales que protegen a las personas frente a las desapariciones forzadas. El experto Salvioli sostuvo que ha habido "mucha sabiduría en el derecho internacional de los derechos humanos, en no haber jamás introducido un mínimo plazo de tiempo de detención para fijar un están-

10 Otros dos miembros del Comité emitieron votos particulares concurrentes en relación con el análisis que hizo el Comité sobre la violación del derecho a la vida (artículo 6 del Pacto). 
dar artificial y fragmentado del crimen de desaparición forzada" (CCPR, 2012d, párr. 13).

Por su parte, la Corte Interamericana de Derechos Humanos ha sostenido que para calificar una conducta como desaparición forzada no importa su duración. Esta consideración le permitió afirmar que el ocultamiento del paradero de una persona que está en poder del Estado, consistente en la falta de identificación y entrega de los restos a sus familiares, durante dos días, constituye desaparición forzada (Corte IDH, 2012, párr. 368). No obstante, la Corte IDH no llegó a esta conclusión interpretando la definición de desaparición forzada consagrada en la Convención Interamericana sobre Desaparición Forzada de Personas, habida cuenta que este tratado no era aplicable al caso porque los hechos a los que se refiere la Corte IDH iniciaron y cesaron en noviembre de 1985, antes de la aprobación de dicha convención, en 1994. La Corte IDH llegó a la conclusión mencionada en su calidad de intérprete de la Convención Americana sobre Derechos Humanos, que, como se ha indicado, no contiene una definición de desaparición forzada, no prohíbe esta práctica y no consagra el derecho a no ser sometido a desaparición forzada.

El caso Yrusta le permitió al Comité contra la Desaparición Forzada, como intérprete auténtico de la Convención internacional para la protección de todas las personas contra las desapariciones forzadas, dejar claro que, en el derecho internacional de los derechos humanos en materia de desaparición forzada, el tiempo que una persona permanezca privada de libertad sin que se sepa donde está no es determinante para caracterizar los hechos como desaparición forzada. En efecto, el Comité, al interpretar la definición de desaparición forzada del artículo 2 de la Convención Internacional, con ocasión del ocultamiento a sus familiares del paradero de Roberto Agustín Yrusta durante más de siete días, sostuvo que la desaparición forzada se constituye con la privación de libertad seguida de la negativa a reconocer dicha privación o del ocultamiento de la suerte o paradero, sustrayéndola de la protección de la ley, "cualquiera sea la duración de dicha privación de libertad u ocultamiento" (CED, 2016, párr. 10.3).

De esta manera, el Comité reafirmó que la característica que identifica una conducta de desaparición forzada y la distingue de otras graves violaciones de derechos humanos como la detención arbitraria es la concurrencia 
de dos conductas: la privación de libertad y el ocultamiento de la suerte o el paradero de la persona, sin que importe el tiempo de dicho ocultamiento.

Bajo la Convención internacional para la protección de todas las personas contra las desapariciones forzadas, para calificar una conducta como detención en secreto no se requiere ningún elemento temporal. Cuando la Convención Internacional dice que nadie será detenido en secreto no agrega plazo alguno. La prohibición de detención en secreto leída en conjunto con la definición de desaparición forzada del artículo 2 -que tampoco somete la conducta prohibida a plazo alguno- apoya la conclusión del Comité, en el sentido que, con cualquier duración, la detención en secreto constituye desaparición forzada.

Bajo la Convención Internacional no son pertinentes las consideraciones según las cuales la sustracción de la protección de la ley debe ser prolongada; tampoco aquellas que indican que la sustracción de la ley es necesaria para que se configure la desaparición forzada. Según el texto de esta Convención, la sustracción de la protección de la ley es una consecuencia de la desaparición forzada y no un requisito para su configuración. La interpretación que hizo el Comité de la definición de desaparición forzada reafirma lo sostenido en el texto convencional: la sustracción de la ley es una consecuencia de la conducta y no un requisito de la misma.

Establecer que la configuración de la desaparición forzada no requiere un elemento temporal no significa banalizar su extrema gravedad ni permitir que conductas menos graves sean consideradas como desapariciones forzadas. Menos aún cuando la Convención Internacional consideró la práctica de la detención en secreto como una modalidad de desaparición forzada. Y es que la detención en secreto pone inmediatamente a la persona por fuera de la protección de la ley, justamente por ser secreta. Como lo advirtió el experto Fabián Salvioli, añadir un requisito temporal a la configuración de la desaparición forzada puede tener la grave consecuencia de demorar la puesta en funcionamiento de los mecanismos de protección urgente previstos en los instrumentos internacionales de protección contra las desapariciones forzadas (CCPR, 2012d, párr. 13).

El Comité, con su interpretación en el caso Yrusta no hizo otra cosa que aplicar al caso bajo examen el marco normativo convencional que, al definir la conducta de desaparición forzada, preserva su extrema gravedad. 
Que la desaparición forzada pueda ser breve o prolongada y que, como en este caso, haya iniciado con una privación de libertad legítima, solo muestra que la privación de libertad seguida del ocultamiento del paradero de la persona puede adquirir diversas modalidades y expresiones.

\section{El derecho de toda persona a no ser detenida en secreto}

La práctica de detener a las personas en secreto ha sido identificada y reprochada por órganos internacionales de protección de derechos humanos como una violación del derecho a la libertad personal y del derecho al reconocimiento de la personalidad jurídica. Sin embargo, su prohibición expresa no había sido reconocida como derecho autónomo en ningún instrumento internacional anterior a la Convención Internacional. Tampoco había sido concebida normativamente como una manera de prevenir las desapariciones forzadas ni como una modalidad de desaparición forzada. La Convención Internacional consagra por primera vez en el derecho positivo internacional el derecho a no ser detenido en secreto. Y opta una vez más por la fórmula de la prohibición absoluta de la conducta como manera de configurar el derecho, al establecer de manera categórica, en el artículo 17.1, que "nadie será detenido en secreto".

En 1994, la Convención interamericana sobre desaparición forzada de personas había logrado un avance importante al afirmar que toda persona privada de libertad debe ser mantenida en lugares de detención oficialmente reconocidos (CISDFP, 1994, artículo XI). Esta norma permite enfrentar la lamentable práctica de detención de personas, sin orden de un juez, por autoridades estatales en lugares clandestinos, que ha sido empleada en varios países de América Latina. No obstante, el nivel de protección logrado con la Convención Internacional es mayor, en la medida en que elabora el deber estatal en forma de prohibición absoluta como un derecho de toda persona a no ser detenida en secreto. Adicionalmente, la formulación de la Convención Internacional pone el énfasis en el carácter secreto de la detención y no solo en la naturaleza del lugar de detención, que, según la Convención Interamericana, debe ser un lugar oficial, para evitar las detenciones clandestinas. 
En el caso Yrusta v. Argentina, el Comité sostuvo que:

[L]os Estados partes están en una posición especial de garante de los derechos de las personas privadas de la libertad, toda vez que las autoridades penitenciarias ejercen un fuerte control o dominio sobre ellas. Por lo tanto, se encuentran especialmente obligados a garantizar a las personas privadas de libertad los derechos establecidos en la Convención y a tomar medidas eficaces para que, entre otras, la privación de la libertad no pueda convertirse en ningún momento en una detención en secreto y desaparición forzada (párr. 10.5).

Teniendo en cuenta que ningún agente del Estado informó a los familiares de Roberto Agustín Yrusta ni a él mismo sobre su traslado ni sobre el lugar donde se encontraba, y que permaneció detenido en forma aislada sin poder comunicarse con nadie durante más de siete días, el Comité consideró que estos hechos constituyeron una violación del derecho de toda persona a no ser detenida en secreto, en incumplimiento del artículo 17.1 de la Convención Internacional.

La anterior conclusión del Comité hace del caso Yrusta el primer pronunciamiento de un comité convencional de la ONU sobre la responsabilidad internacional del Estado por la violación de la prohibición de detener personas en secreto. Como se dijo, hasta entonces esta prohibición no tenía consagración en un tratado internacional.

El caso muestra además que la detención en secreto puede ocurrir en una prisión oficial y no solo en un lugar clandestino de detención. Cuando las autoridades garantes de sus derechos no suministran información sobre el paradero de la persona que está legítimamente en poder del Estado, como en este caso, en que las autoridades judiciales y penitenciarias argentinas no informaron, por más de siete días, sobre el traslado de prisión ni sobre el lugar de reclusión al que fue llevado el señor Yrusta, se viola la prohibición de no ser detenido en secreto.

De esta manera, el caso hace evidente el avance que representa la Convención Internacional, en el sentido que el deber de mantener a las personas privadas de libertad en lugares de detención oficiales no es suficiente para prevenir una desaparición forzada. El deber adicional de asegurar que 
ninguna persona sea detenida en secreto fortalece, sin duda, la protección internacional. No se trata solamente de que el lugar de detención sea oficial. Además, el lugar de detención debe ser conocido, en todo momento, por la persona privada de libertad, por sus familiares y por otras personas con interés legítimo, así como por las autoridades estatales con competencias para vigilar y controlar a aquellas encargadas de las personas privadas de libertad.

Por otra parte, el caso Yrusta v. Argentina confirma, por la vía de las decisiones en casos individuales, lo que ya el Comité había afirmado en relación con la prohibición de detención en secreto. Entre otras, en sus observaciones finales sobre Irak, en relación con las alegaciones de práctica de la detención secreta en este país (negadas por el Estado), el Comité recomendó clausurar inmediatamente o convertir en un centro de detención ordinario cualquier centro de detención secreta o lugar donde haya personas sometidas a detención secreta (CED, 2015, párr. 29).

\section{La obligación de establecer y mantener registros oficiales de las personas privadas de libertad}

Las autoridades penitenciarias argentinas no registraron el día y la hora del traslado del señor Yrusta; tampoco el lugar de destino, ni la autoridad que ordenó el traslado ni la encargada de realizarlo. En los registros carcelarios, el señor Yrusta aparece con tres nombres distintos (Roberto Agustín Yrusta, Mario Alejandro Ríos o David Salvador Torres), lo que ciertamente dificultó tener certeza sobre su ubicación durante las diferentes fases de su detención (CED, 2016, párr. 10.2).

La conducta de los agentes del Estado desconoció lo dispuesto en el artículo 17.3.h) de la Convención Internacional sobre el deber de registrar "[e]l día y la hora de la liberación o del traslado a otro lugar de detención, el destino y la autoridad encargada del traslado".

En la Convención Internacional, la prohibición de detención en secreto, en su dimensión de medida para prevenir las desapariciones forzadas, se complementa con otras medidas de carácter preventivo como el deber de establecer y mantener registros oficiales de personas privadas de libertad, 
que contengan, por lo menos, la información que el artículo 17.3 indica, relacionada con: i) la persona privada de la libertad (su identidad e información sobre su integridad física); ii) las circunstancias de la privación de la libertad (día, hora, lugar y motivos de tal privación); iii) las autoridades que intervienen en la privación de la libertad (quien la ordena, quien la realiza y quien la controla); iv) donde permanece la persona privada de la libertad (lugar de privación de la libertad, día y hora de admisión en ese lugar y la autoridad responsable del sitio); v) las circunstancias que modifiquen la privación de la libertad o el lugar donde se lleva a cabo (día y hora de la liberación o traslado y en este último caso, el nuevo destino y la autoridad encargada de hacerlo y vi) en caso de fallecimiento de la persona privada de la libertad, los motivos del deceso y el destino del cuerpo de la persona fallecida.

Al pronunciarse sobre la obligación convencional de establecer y mantener registros oficiales de las personas privadas de libertad, el Comité recordó a los Estados partes de la Convención Internacional que "tienen la obligación de garantizar que la información relevante sobre la privación de la libertad y el desarrollo de la detención sea disponible en registros detallados y accesibles" (CED, 2016, párr. 10.5).

Los hechos del caso y el dictamen del Comité reflejan el vínculo entre la existencia de registros oficiales que contengan la información indicada en la Convención Internacional y la prevención de detenciones secretas. En efecto, si los registros oficiales de personas privadas de libertad incluyen al menos la información a que se refiere el artículo 17.3 de la Convención Internacional ello, en sí mismo, puede evitar que el paradero de las personas privadas de libertad se oculte a sus familiares. Dicho de otra manera, así se puede evitar que las personas desaparezcan estando en poder del Estado.

También relacionado con la prevención de detenciones secretas, los hechos del caso Yrusta le permitieron al Comité disponer una medida de reparación de carácter general, que tiene impacto más allá de la situación del señor Yrusta. El Comité requirió al Estado de Argentina que tome las medidas necesarias para hacer efectivas las garantías de no repetición que la Convención Internacional establece, incluida "la organización y mantenimiento de registros de conformidad con lo estipulado en la Convención" (CED, 2016, párr. 12.e). Esta medida de reparación busca garantizar que hechos similares a aquellos de los que fue víctima el señor Yrusta no se repitan. En 
particular, está orientada a que el Estado pueda corregir las deficiencias en el registro de los traslados y de la identidad de las personas privadas de libertad.

Como complemento de la medida de reparación mencionada, el Comité requirió al Estado que difunda ampliamente el contenido del dictamen, "en particular, pero no exclusivamente, entre los miembros de las fuerzas de seguridad y el personal penitenciario encargados de cuidar y atender a las personas privadas de libertad" (CED, 2016, párr. 13).

Esta medida de reparación tiene un carácter preventivo y uno de no repetición, por cuanto el conocimiento de los hechos y de las conclusiones del dictamen del caso Yrusta, por parte del personal penitenciario, permite que se implementen mecanismos y prácticas para evitar la repetición de hechos similares en el futuro.

\section{El derecho de acceso a la información que reposa en registros oficiales de personas privadas de libertad}

Una de las formas para prevenir detenciones secretas y desapariciones forzadas, expresada en la Convención Internacional, como se mencionó anteriormente, se concreta en la obligación de los estados de establecer y mantener registros oficiales de personas privadas de la libertad. Esta sola obligación no es suficiente, puesto que, para que la prevención sea efectiva, se requiere, además, que las personas con interés legítimo -allegadas y allegados, familiares, abogadas y abogados- tengan derecho de acceder a cierta información relativa a la privación de la libertad. De no ser así, la obligación de mantener dichos registros no puede desplegar toda su potencialidad protectora.

La Convención Internacional garantiza a las personas con interés legítimo el acceso a la información relacionada con: la decisión de privación de la libertad (la autoridad que la ordena, fecha, hora y lugar de la privación); la autoridad que controla la privación de libertad; el sitio de privación de libertad (admisión de la persona, dónde se encuentra y, en caso de traslado, destino y autoridad responsable del mismo); los aspectos relacionados con la salud; en caso de fallecimiento, sus circunstancias y causas y, sobre la liberación de la persona privada de libertad, cuando ello suceda (ONU, 2006, artículo 18). 
En el caso Yrusta, el Comité, luego de confirmar que sus familiares "no recibieron información sobre el lugar en el que se encontraba ni tan siquiera que había sido trasladado a otro centro penitenciario", consideró que "la privación de información sufrida durante un periodo de más de siete días por el Sr. Yrusta y sus familiares, incluyendo las autoras [de la comunicación ante el Comité] constituye por sí una violación” de los derechos a no ser detenido en secreto, a tener acceso a cierta información que reposa en los registros oficiales de personas privadas de libertad y el desconocimiento de las excepciones que se pueden imponer al ejercicio del anterior derecho, en violación de los artículos 17(1), 18 y 20(1) de la Convención Internacional (CED, 2016, párr. 10.6).

En el caso sometido a conocimiento del Comité, la falta de respuesta y de información sobre el paradero de una persona privada de libertad durante siete días configuró dos violaciones. Por una parte, según el Comité, la falta de información se constituye en uno de los elementos de la desaparición forzada: el ocultamiento del paradero de la persona. Además, es una violación autónoma del derecho de los familiares y allegados a recibir información sobre "el lugar donde se encuentra la persona privada de libertad y, en caso de traslado hacia otro lugar de privación de libertad, el destino y la autoridad responsable del traslado" (ONU, 2006, artículo 18.d). El Estado entonces incumplió, con la misma omisión de información, su obligación de respeto, consistente en no someter a nadie a desaparición forzada, y su obligación de garantía, que radica en asegurar el acceso a información sobre el traslado.

El dictamen del Comité, con base en los hechos del caso Yrusta, puso de presente la importancia de haber plasmado en la Convención Internacional el derecho de los familiares y allegados a acceder a la información a la que se refiere su artículo 18, como medida preventiva ante las desapariciones forzadas. Conocer esta información es crucial para evitar detenciones en secreto y otras formas de desapariciones forzadas. Como se ha mencionado, la privación de información sobre el traslado y la imposibilidad del señor Yrusta de comunicarse con sus familiares durante más de siete días, configuraron una detención en secreto. Y a la vez, esa misma falta de información "sobre lo ocurrido durante los más de siete días en los cuales el paradero del Sr. Yrusta quedó desconocido, constituyen un ocultamiento 
de su suerte y paradero" (CED, 2016, párr. 10.4) que configuró una desaparición forzada.

El derecho de los familiares y allegados de acceder a la información sobre la decisión de privación de libertad, la autoridad que controla dicha privación, el sitio de privación de libertad, incluida aquella sobre los traslados, es tan importante que la Convención Internacional, si bien permite la limitación excepcional del acceso a esta información, expresamente afirmó que "en ningún caso se admitirán limitaciones al derecho a las informaciones previstas en el artículo 18 que puedan constituir conductas definidas en el artículo 2 o violaciones del párrafo 1 del artículo 17" (ONU, 2006, artículo 20). En la lógica de la Convención Internacional, no se puede limitar el derecho de acceso a la información prevista en el artículo 18 cuando dicha limitación pueda constituir una de las conductas que configuran la desaparición forzada, como el ocultamiento de la suerte o paradero, o una violación del derecho a no ser detenido en secreto.

\section{La obligación de investigar la desaparición forzada independientemente de la posterior muerte}

Según los hechos puestos en conocimiento del Comité, las autoridades argentinas iniciaron una investigación penal únicamente por la muerte de Roberto Agustín Yrusta. El ocultamiento de su paradero durante siete días, con ocasión de un traslado, mientras estaba privado de libertad y en poder de las autoridades penitenciarias y judiciales de su país, no dio lugar al inicio de ninguna investigación penal. El Comité constató lo anterior afirmando que las investigaciones iniciadas "se han centrado en las causas y circunstancias" de la muerte del señor Yrusta, mientras que "su alegada desaparición durante más de siete días no está referida en ninguno de los expedientes comunicados en el contexto de la presente comunicación" (CED, 2016, párr. 10.9). La omisión estatal de investigar los hechos denunciados como desaparición forzada configuró, en criterio del Comité, una violación de la obligación consagrada en el artículo 12.1 de la Convención Internacional de examinar de manera rápida e imparcial la denuncia y proceder sin demora, si fuere el caso, a realizar una investigación exhaustiva e imparcial. 
Con base en los hechos presentados por las autoras de la comunicación, y como medida para reparar el incumplimiento de la obligación de investigar en los términos previstos en la Convención Internacional, el Comité requirió al Estado que la investigación en el caso Yrusta no se limite a establecer las causas de su muerte, sino que además "integre la investigación exhaustiva e imparcial de su desaparición con ocasión de su traslado de Córdoba a Santa Fe" (CED, 2016, párr. 12.b).

Esta medida de reparación tiene una importancia que trasciende el caso Yrusta. Lo dispuesto por el Comité es un aporte importante hacia la superación de la cultura judicial existente en varios países, según la cual, cuando una persona es encontrada sin vida solo se investiga su muerte, sin importar si esta estuvo precedida de una desaparición forzada. Esta práctica judicial pareciera estar fundada en una arraigada y errónea creencia de que la muerte anula o elimina la desaparición forzada que la precedió. Aunque esta conducta haya cesado, como en el caso del señor Yrusta, la investigación penal debe dar cuenta de que se trata de dos delitos que se cometieron en forma sucesiva (primero la desaparición forzada y luego de que esta cesó, la muerte) y no de uno solo, el de homicidio, que absorbe o anula el de desaparición forzada.

La amplia difusión del caso Yrusta v. Argentina puede contribuir entonces a cambiar esta equivocada práctica de las instituciones encargadas de la investigación penal, que torna invisible la desaparición forzada frente a la muerte que ocurre luego de que la primera conducta delictiva ha cesado.

\section{El papel de las autoras de la comunicación presentada al Comité contra la Desaparición Forzada}

Los peticionarios de un caso y sus representantes, en general, tienen un papel importante en presentar casos que además de ofrecer una respuesta a la situación concreta, permitan a los órganos internacionales interpretar y aplicar los tratados internacionales de derechos humanos.

En el caso Yrusta v. Argentina, los importantes avances comentados en este artículo en la interpretación y aplicación de la Convención Internacional no son mérito exclusivo del Comité contra la Desaparición Forzada. 
La falta de información sobre el paradero del señor Yrusta durante más de siete días, en el contexto de su traslado de un establecimiento penitenciario a otro, y la imposibilidad de sus hermanas de comunicarse con él durante ese tiempo, a pesar de los reiterados pedidos, fue entendida y elaborada jurídicamente como una desaparición forzada por el representante de las autoras, el Defensor Provincial de Santa Fe.

La acertada decisión del Defensor Provincial de Santa Fe de presentar la comunicación sobre los hechos cometidos en perjuicio de Roberto Agustín Yrusta ante el Comité contra la Desaparición Forzada y no ante el Comité de Derechos Humanos, le permitió al primero interpretar y aplicar varias de las disposiciones que representan importantes avances en la protección internacional contra la abominable práctica de desaparición forzada de personas, instituidas en el primer tratado de alcance universal en la materia: la Convención internacional para la protección de todas las personas contra las desapariciones forzadas.

\section{Conclusión}

Las condiciones de la desaparición forzada de Roberto Agustín Yrusta, como se ilustró en este artículo, le permitieron al Comité contra la Desaparición Forzada, por primera vez desde su conformación, aplicar e interpretar en un caso concreto algunos de los nuevos derechos que aparecen en la Convención internacional para la protección de todas las personas contra las desapariciones forzadas, como los derechos de toda persona a no ser sometida a desaparición forzada y a no ser sometida a esa modalidad de desaparición forzada que es la detención en secreto.

Dichas condiciones también le permitieron al Comité pronunciarse sobre la importancia del deber estatal de establecer y mantener registros oficiales de personas privadas de libertad y garantizar el derecho de los familiares y allegados a la información que reposa en esos registros, en particular, aquella relacionada con los traslados, como formas de prevención de la desaparición forzada.

El caso Yrusta le dio igualmente al Comité la oportunidad de ratificar, con fundamento en un tratado internacional específico, que para la confi- 
guración de la desaparición forzada no se requiere ni se exige el transcurso de ningún plazo y que las detenciones en secreto por un periodo breve, como aquella a la que fue sometido Roberto Agustín Yrusta, son también desapariciones forzadas.

El Comité tuvo ocasión de destacar, asimismo, la importancia de investigar la desaparición forzada como tal, con independencia de otras violaciones de derechos humanos cometidas en perjuicio de Roberto Agustín Yrusta, como la tortura y su posterior muerte. Lo anterior constituye una regla que deben seguir las autoridades estatales, que en muchas situaciones de desaparición forzada seguida de muerte únicamente investigan la muerte, olvidándose del derecho de las víctimas a la justicia y a la reparación por la desaparición forzada.

\section{Bibliografía}

Asamblea General de la Organización de Estados Americanos (OEA). (1994). Convención interamericana sobre desaparición forzada de personas (CISDFP). Belém do Pará: 9 de junio.

Asamblea General de la Organización de las Naciones Unidas (ONU). (1992). Declaración sobre la protección de todas las personas contra las desapariciones forzadas. Resolución 47/133. Nueva York: 18 de diciembre.

Asamblea General de la Organización de las Naciones Unidas (ONU). (2006). Convención internacional para la protección de todas las personas contra las desapariciones forzadas. Resolución 61/177. Nueva York: 20 de diciembre.

Citroni, G. (2016). Short-term enforced disappearances as a tool for repression. En Quaderni di SIDIBlog. il blog della Società italiana di Diritto Internazionale e di Diritto dellÚnione europea, V.3, 182-187.

Comisión de Derechos Humanos (CDH). (1980). Resolución 20 (XXXVI), 29 de febrero.

Comité contra la Desaparición Forzada (CED). (2015). Observaciones finales sobre el informe presentado por el Iraq en virtud del artículo 29, párrafo 1, de la Convención. Doc. CED/C/IRQ/CO/1, 13 de octubre. 
Comité contra la Desaparición Forzada (CED). (2016). Yrusta v. Argentina. Dictamen aprobado por el Comité en virtud del artículo 31 de la Convención, respecto de la comunicación num. 1/2013. Doc. CED/ C/10/D/1/2013, 11 de marzo.

Comité de Derechos Humanos (CCPR). (1980). Ismael Weinberger v. Uruguay, Comunicación No. R.7/28, 29 de octubre.

Comité de Derechos Humanos (CCPR). (1981). Rosario Pietraroia v. Uruguay, Comunicación No. R.10/44, 27 de marzo.

Comité de Derechos Humanos (CCPR). (1982). Eduardo Bleier v. Uruguay, Comunicación No. R.7/30, 29 de marzo de 1982.

Comité de Derechos Humanos (CCPR). (1983). Quinteros v. Uruguay. Comunicación No 107/1981. Doc. CCPR/C/19/D/107/1981, 21 de julio. Comité de Derechos Humanos (CCPR). (2003). Sarma v. Sri Lanka. Comunicación No 950/2000. Doc. CCPR/C/78/D/950/2000, 31 de julio. Comité de Derechos Humanos (CCPR). (2006). Bousroual v. Argelia. Comunicación No 992/2001. Doc. CCPR/C/86/D/992/2001, 30 de marzo.

Comité de Derechos Humanos (CCPR). (2007a). Grioua v. Algeria. Comunicación No 1327/2004. Doc. CCPR/C/90/D/1327/2004, 10 de julio.

Comité de Derechos Humanos (CCPR). (2007b). Kimouche v. Algeria. Comunicación No 1328/2004. Doc. CCPR/C/90/D/1328/2004, 10 de julio.

Comité de Derechos Humanos (CCPR). (2012a). Aboufaied v. Libia. Comunicación No 1782/2008. Doc. CCPR/C/104/D/1782/2008, 21 de marzo.

Comité de Derechos Humanos (CCPR). (2012b). Aboufaied v. Libia. Comunicación No 1782/2008. Doc. CCPR/C/104/D/1782/2008, 21 de marzo. Sir Nigel Rodley. Voto particular coincidente.

Comité de Derechos Humanos (CCPR). (2012c). Aboufaied v. Libia. Comunicación No 1782/2008. Doc. CCPR/C/104/D/1782/2008, 21 de marzo. Walter Kälin. Voto particular parcialmente disidente.

Comité de Derechos Humanos (CCPR). (2012d). Aboufaied v. Libia. Comunicación No 1782/2008. Doc. CCPR/C/104/D/1782/2008, 21 de marzo. Fabián Omar Salvioli. Voto particular parcialmente disidente. 
Comité de Derechos Humanos (CCPR). (2015). Rosa María Serna $y$ otros v. Colombia. Comunicación No 2134/2012. Doc. CCPR/ C/114/D/2134/2012, 9 de julio.

Comité de Derechos Humanos (CCPR). (2019). Christian Téllez Padilla v. México. Comunicación 2750/2016. Doc. CCPR/C/126/D/2750/2016, 15 de julio.

Corte Interamericana de Derechos Humanos (Corte IDH). (1988). Caso Velásquez Rodríguez v. Honduras. Sentencia de 29 de julio.

Corte Interamericana de Derechos Humanos (Corte IDH). (2006). Caso Goiburú y otros vs. Paraguay. Sentencia de Fondo y Reparaciones, 22 de septiembre.

Corte Interamericana de Derechos Humanos (Corte IDH). (2014). Caso Rodríguez Vera y otros (Desaparecidos del Palacio de Justicia) vs. Colombia. Sentencia de Excepciones Preliminares, Fondo y Reparaciones, 14 de noviembre.

Estatuto de Roma de la Corte Penal Internacional. (1998). Roma: 17 de julio de 1988.

Galvis M. (2020a). Rights Related to Enforced Disappearance: New Rights in the International Convention for the Protection of All Persons from Enforced Disappearances. En A. Von Arnaud, K. Von der Decken y M. Susi (editors). The Cambridge Handbook of New Human Rights. Recognition, Novelty, Rethoric (pp. 415-427). Cambridge: Cambridge University Press.

Galvis, M. (2020b). De Velásquez Rodríguez a los Principios Rectores para la Búsqueda de Personas Desaparecidas. En J. Ibáñez, R. Flores y J. Padilla (coords). Desaparición Forzada en el Sistema Interamericano de Protección de Derechos Humanos. Balance, Impacto y Desafíos (pp. 333-373). México: Instituto de Estudios Constitucionales del Estado de Querétaro e Instituto Interamericano de Derechos Humanos. 